\title{
Direitos humanos: a crítica visão popular brasileira nas duas décadas após o governo militar
}

Human rights: the critical view of the Brazilian population in the two decades after the military governments

Derechos humanos: la opinión crítica popular brasileña en las dos décadas después del gobierno militar

Recebido: 13/08/2021 | Revisado: 18/08/2021 | Aceito: 22/08/2021 | Publicado: 23/08/2021

Diego Paulo de Oliveira Romualdo
ORCID: https://orcid.org/0000-0003-4239-6675
Faculdade de Administração da Universidade Federal de Minas Gerais, Brasil
E-mail: capitaoromualdo@ gmail.com
Iris Barbosa Goulart
ORCID: https://orcid.org/0000-0003-1088-3268
E-mail: irisbgoulart@ gmail.com
Henrique da Silveira Zanin
Faculdade de Educação da Universidade Federal de Minas Gerais, Brasil
ORCID: https://orcid.org/0000-0002-1991-4270
Faculdade de Direito da Universidade de São Paulo, Brasil
E-mail: henriquezanin@ outlook.com

\begin{abstract}
Resumo
Analisa-se nesta pesquisa o significado e a importância dos direitos humanos no Brasil segundo a própria população do país quanto aos temas da liberdade de crença e da atuação das forças policiais. Assim, contextualizam-se a evolução dos direitos humanos no cenário político brasileiro da época. Trata-se de uma pesquisa qualitativa, que adota revisão bibliográfica e coleta de informações documentais, reunindo dados buscados no espaço reservado aos leitores de uma revista popular brasileira. O período escolhido foi o compreendido entre os anos de 1985 e 2004, ou seja, após o período do governo militar, que durou de 1964 a 1985. O corte temporal se justifica por se tratar de um período em que o tema Direitos Humanos teve grande repercussão no Brasil, por motivos políticos. Para estudo dos resultados coletados, a pesquisa se vale da análise de conteúdo e usa a categorização para proceder à revisão das opiniões emitidas pelos leitores. Infere-se que a liberdade de expressão dos leitores foi também utilizada como forma de amplificação de vozes e ideias sobre os assuntos aqui delimitados. Pôde-se ainda perceber que o a maioria católica deu lugar à pluralidade religiosa no período retratado e que as críticas sobre a violência policial se estenderam por todo o período analisado, culminando em reestruturações e implementações de novas políticas públicas.
\end{abstract}

Palavras-chave: Direitos humanos; Liberdade de crença; Liberdade de expressão; Forças policiais; Revista ISTOÉ.

\begin{abstract}
The main objective of this work is to analyse the meaning and importance of human rights in Brazil when seen from the perspective of the population regarding themes such as freedom of belief and the performance of police forces. The issue of human rights in contemporary Brazilian history is therefore approached, contextualizing it in the Brazilian political scenario at that time. This qualitative research adopts bibliographic review and collection of documentary information, gathering data sought in the space reserved for readers of a popular Brazilian magazine between the 1980s and the 2000s. The period chosen was between 1985 and 2004, that is to say, exactly two decades after the end of the period marked by the Brazilian civil-military dictatorship, which took place from 1964 to 1985 , period in which the human rights theme had great repercussion in Brazil, for political reasons. This research makes use of content analysis and uses categorization in order to review the opinions expressed by readers. It is inferred that the readers' freedom of expression was also used as a way of amplifying voices and ideas on the subjects delimited here. It could also be seen that the Catholic majority gave way to religious plurality in the period portrayed and that criticism of police violence extended throughout the analysed period, culminating in restructuring and implementation of public policies to improve police forces.
\end{abstract}

Keywords: Human rights; Freedom of belief; Freedom of expression; Police forces; ISTOÉ Magazine.

\section{Resumen}

Esta investigación analiza el significado y la importancia de los derechos humanos en Brasil de acuerdo con la propia población del país en relación con los temas de la libertad de creencia y el desempeño de las fuerzas policiales. Así, se 
contextualiza la evolución de los derechos humanos en el escenario político brasileño en ese momento. Se trata de una investigación cualitativa, que adopta una revisión bibliográfica y recopilación de información documental, recogiendo datos buscados en el espacio reservado a los lectores de una popular revista brasileña. El período elegido fue entre 1985 y 2004, es decir, posterior al período de gobierno militar, que duró de 1964 a 1985. Repercusión en Brasil, por razones políticas. Para estudiar los resultados recopilados, la investigación utiliza el análisis de contenido y la categorización para revisar las opiniones expresadas por los lectores. Se infiere que también se utilizó la libertad de expresión de los lectores como una forma de amplificar voces e ideas sobre los temas aquí delimitados. También se pudo observar que la mayoría católica dio paso a la pluralidad religiosa en el período retratado y que la crítica a la violencia policial se extendió a lo largo del período analizado, culminando en la reestructuración e implementación de nuevas políticas públicas.

Palabras clave: Derechos humanos; Libertad de creencias; Libertad de expresión; Fuerzas policiales; Revista ISTOÉ.

\section{Introdução}

Em 10 de dezembro de 1948, a Declaração Universal dos Direitos Humanos (Declaração) foi aprovada unanimemente pela Assembleia Geral das Nações Unidas, primeira organização internacional a abranger a maioria das nações. Tal acontecimento constituiu o marco inicial da retomada da proteção de direitos por um sistema internacional, inaugurando a concepção contemporânea de direitos humanos. De acordo com essa declaração, todas as pessoas nascem livres e iguais em dignidade e direitos.

A consciência sobre os direitos humanos se define e se torna um conceito indispensável ao passo que uma sociedade adquire maturidade, impondo análise da efetiva aplicação e implicações sociais daqueles. Embora a preocupação com os direitos humanos se evidencie em diferentes momentos da história do Brasil, ela se tornou muito relevante na década de 1980, quando significativas mudanças se efetivaram no campo político e legislativo do país, o que culminou com a promulgação da Constituição Federal de 1988. Trata-se, pois, de assunto atual, cujos reflexos se fazem presentes ainda nesta segunda década dos anos 2000, refletindo a complexidade do conceito dos direitos humanos, e sua implicação entre pessoas, instituições e nações.

Este trabalho tem como principal objetivo analisar o significado e a importância dos direitos humanos no Brasil quando visto pela ótica da população quanto aos temas da liberdade de crença e da atuação das forças policiais nacionais. O período escolhido para essa análise foi o compreendido entre os anos de 1985 e 2004, ou seja, exatas duas décadas após o fim do período marcado pela ditadura civil-militar brasileira, que aconteceu de 1964 a 1985 . Essa escolha temporal se justifica pelo interesse acadêmico sobre uma possível mudança de entendimento da população brasileira ao longo desses vinte anos escolhidos para análise, já que tanto o papel das forças policiais quanto aqueles que professavam outras fés que não a cristã católica eram alvos de crítica e rejeição. Para isso, aborda-se a questão dos direitos humanos na história contemporânea, contextualizando-a no cenário político brasileiro à época, a partir de manifestações de leitores no espaço de uma revista popular de grande circulação nacional.

O texto que apresenta a pesquisa se compõe das seguintes partes: a primeira consiste nesta introdução ao tema abordado neste trabalho. A segunda parte aborda a evolução dos direitos humanos enquanto campo próprio de estudo, bem como a sua introdução na história brasileira da segunda metade do século XX. A terceira trata dos procedimentos metodológicos utilizados. A quarta parte, que se subdivide em quatro partes, se detém a apresentar e analisar as manifestações de leitores e a última parte apresenta as considerações finais deste artigo.

\section{A Evolução dos Direitos Humanos e a História Brasileira}

Antes de tudo, é oportuno esclarecer o sentido da expressão direitos humanos, que consistem em direitos básicos garantidos a todo e qualquer indivíduo. Portanto, eles devem ser universais, isto é, devem se estender a pessoas de todos os povos e nações, independentemente de sua classe social, etnia, gênero, nacionalidade ou posicionamento político (Freitas \& 
Piovesan, 2011; Trindade, 2010). A Organização das Nações Unidas (ONU) inclui nesse conceito o direito à vida, direito à liberdade de expressão, direito à integridade física, direito à dignidade, direito a crenças religiosas, direito a diferentes posicionamentos políticos. O rol de direitos tem, ainda, sido ampliado ao longo dos anos por novos instrumentos internacionais aprovados desde os anos 1940.

Embora os direitos humanos constituam garantias históricas, eles se transformam ao longo do tempo, adaptando-se às necessidades específicas de cada momento e se aperfeiçoando ao longo da história (Zanin, 2021). Comparato (2019) reconhece uma divisão temporal da história delineada por Karl Jaspers (1949). Essa divisão fez referência a um suposto período na história mundial denominado período axial, compreendido entre os anos 600 a.C. e 480 a.C., a partir do qual uma nova cosmovisão a respeito da vida foi divulgada por grandes doutrinadores em diferentes partes do mundo, os quais passaram a divulgar ensinamentos fundamentais para a vida. De acordo com Jaspers (1949), é no período axial que os mitos religiosos passaram a ser questionados, exigindo um novo padrão para guiar as ações humanas. Desde então, o ser humano teria se tornado paulatinamente o centro das reflexões sobre suas próprias ações. Assim, todos os seres humanos seriam essencialmente iguais entre si, independente de suas diferenças. Este argumento, por si só, proporia a premissa de que existem direitos universalizantes que decorrem do simples fato de seus detentores existirem como seres humanos.

Os direitos humanos são então introduzidos como princípios nas constituições ocidentais modernas, estando a dignidade humana presente em diversos textos aprovados após a Segunda Guerra Mundial (Barroso, 2013). Para Bobbio (2004), o reconhecimento da existência desses direitos decorre de uma inversão de perspectiva sobre a importância do indivíduo frente o poder do Estado que possui rol fluido, que pode sofrer alterações conforme a época e a civilização que os demanda. Em épocas anteriores, o Estado possuía a precedência sobre os indivíduos, tendo sido essa ordem alterada num processo irreversível. Ainda, grupos de pessoas passaram a lutar para terem liberdades e direitos reconhecidos e ampliados, o que possibilitou o fortalecimento de direitos ao longo do tempo (Messer, 1997). Em outras ocasiões, o aumento do poder dos grupos dominantes representou ameaça às liberdades de grupos minoritários, levando estes últimos a exigirem limitações e intervenções do Estado, capazes de lhes garantir proteção.

Para Piovesan (2014), a Declaração traz a chamada concepção contemporânea, que é marcada pela universalidade e indivisibilidade desses direitos, bem como a observância de mínimo ético irredutível. No período em que foi promulgada a Declaração Universal dos Direitos Humanos, o Brasil vivia a experiência do final da Segunda Grande Guerra e a mudança decorrente da deposição de Getúlio Vargas, em 29 de Outubro de 1945, após uma ditadura que se iniciou em 1930. Após a queda de Getúlio, foi eleito Eurico Gaspar Dutra, que governou de 1946 a 1951, dando início ao período de 21 anos denominado Quarta República. Nesse período, foi promulgada a Constituição de 1946, a qual trouxe melhorias em questões democráticas, tendo restabelecido direitos que haviam sido suspensos durante o governo Vargas. Houve a ampliação do número de eleitores no Brasil, mas os analfabetos se mantiveram excluídos do direito ao voto, só o reconquistando pela Constituição de 1988.

Após o governo Dutra, Getúlio foi eleito democraticamente e realizou um governo marcado pelo populismo, defendendo os direitos dos trabalhadores urbanos, mediante leis que definiram questões relacionadas à jornada de trabalho, aos direitos trabalhistas, aos salários e à previdência social. Em 1954, pressionado pela alta inflação e pelas críticas ao seu governo, Getúlio cometeu suicídio. Sucedeu-se uma fase em que vários presidentes exerceram mandatos curtos, até que foi eleito Juscelino Kubitscheck de Oliveira, cujo mandato foi de 1956 a 1961. Este presidente impôs um projeto intenso conhecido como Plano de Metas, que incluiu a transferência da capital federal do Rio de Janeiro para a cidade de Brasília. Houve um investimento na modernização econômica, mediante industrialização do país e construção de grande malha rodoviária, visando ligar todos os estados á nova capital. 
Jânio Quadros foi um professor paulista eleito para suceder Juscelino, que não conseguiu estabelecer boas relações com o Congresso Nacional, renunciando em 1962. A posse do vice-presidente João Goulart não agradou às Forças Armadas e grupos civis que o consideravam inapto. Protestos desses grupos e decisões tomadas pelas lideranças militares levaram à declaração do cargo de presidente como vago. João Goulart deixou o país em 1964, e militares assumiram o governo.

O período transcorrido entre 1964 e 1985 se caracterizou pela repressão às manifestações relacionadas à defesa da democracia. Estudantes, trabalhadores e demais opositores do governo militar que lideravam tais movimentos eram considerados subversivos, sendo investigados, presos, exilados ou tendo desaparecido (Zanin \& Soto, 2019), havendo ainda uma censura rigorosa na área das artes e da educação.

A partir do ano de 1985, iniciou-se a passagem do governo militar para o modelo de eleição democrática, o que culminou na maior mudança legislativa do estado brasileiro - a promulgação da nova Constituição Federal, em 1988 (Constituição). A nova Carta Magna incorporou textos contendo uma ampla gama de direitos e garantias individuais já defendidos nas declarações e pactos internacionais de direitos humanos, dentre outros documentos internacionais de defesa das garantias fundamentais. Vigente até os dias atuais, a Constituição trouxe um vasto rol de direitos e garantias fundamentais, tendo transformado a prevalência dos direitos humanos num dos pilares que sustentariam as relações internacionais do Brasil com outros estados. Em virtude disso, o Brasil tem aderido a importantes pactos e convenções de defesa dos direitos humanos (Brasil, 1996).

Além da liberdade de culto, por exemplo, a Constituição de 1988 deu ainda grande importância à liberdade de expressão, que fora cerceada durante o período dos governantes militares. A manutenção da ordem e a atuação dos responsáveis pela segurança da população também sofreu significativas mudanças a partir do final do governo militar e da redemocratização do país. Críticas a atos que feriam liberdades passaram a constituir alvo de críticas e denúncias, mostrando uma retomada da luta explícita pelos direitos humanos, sufocada por décadas.

No campo das legislações federais, foi proposto o Projeto de Lei n. ${ }^{\circ}$ 5.239/90, que pretendeu alterara Lei n. ${ }^{0} 7.716 / 89$, elaborada para criminalizar práticas discriminatórias e preconceituosas baseadas em questões étnico-raciais e religiosas. Três meses depois, foi aprovada a Lei n. ${ }^{\circ} 8.081 / 90$, que acrescentou questões baseadas em nacionalidade à lei anterior. Tais medidas também se infiltraram nos governos estaduais, e em 1994, em Minas Gerais, foi sancionado o Decreto Estadual n. ${ }^{\circ}$ 35.661/94, que tratava do Regimento Interno do Conselho Estadual de Defesa dos Direitos Humanos. Este dispositivo legal regulamentava a estrutura do conselho, que tinha como finalidade promover investigações e estudos sobre questões relacionadas aos direitos humanos, inclusive quanto a representações às autoridades policiais ou ao Ministério Público, buscando apurar e impor sanções disciplinares ou penais aos agentes das forças policiais que praticassem atos de violação dos direitos humanos (Minas Gerais, 1994a).

Em 1996, foi lançado o Programa Nacional de Direitos Humanos (Brasil, 1996), endereçando assuntos afetos às forças policiais, que causariam "entraves à cidadania plena, que levam à violação sistemática dos direitos, visando a proteger o direito à vida e à integridade física; o direito à liberdade; o direito à igualdade perante a lei” (Brasil, 1996, p. 12). O Programa também conta com propostas relacionadas à atividade policial como:

Incluir nos cursos das academias de polícia matéria específica sobre direitos humanos (Brasil, 1996, p. 16). [...] Implementar a formação de grupos de consultoria para educação em direitos humanos, conforme o protocolo de intenções firmado entre o Ministério da Justiça e a Anistia Internacional (Brasil, 1996, p. 16). [...] Apoiar as experiências de polícias comunitárias ou interativas, entrosadas com conselhos comunitários, que encarem o policial como agente de proteção dos direitos humanos (Brasil, 1996, p. 17). [...] Propugnar pela aprovação do projeto de Lei n. ${ }^{\circ}$ 4.716-A/94 que tipifica o crime de tortura (Brasil, 1996, p. 19). 
Ao analisar esses tópicos, infere-se que a principal preocupação governamental relacionada às forças policiais era a necessidade de eliminação da tortura, marca dos governos ditatoriais, e que a principal estratégia de intervenção passou a ser a educação adequada durante o processo de formação profissional dos policiais.

Em termos de políticas públicas, o Governo Federal lançou o Plano Nacional de Segurança Pública - PNSP (Brasil, 1996), que criava o Fundo Nacional de Segurança Pública, cujo papel era apoiar os estados no financiamento desses investimentos. Em 2002, foi lançado ainda o Plano Nacional de Direitos Humanos - Fase II (PNDH-II), mais amplo que o primeiro, lançado em 1996. As 518 (quinhentas e dezoito) propostas buscaram garantir o direito à vida, à justiça, à liberdade, à orientação sexual, à igualdade, à educação, à saúde e previdência social, ao trabalho, à moradia, à alimentação, à cultura e lazer, dentre outros.

O PNDH-II continuou investindo na estratégia educacional. Considerava importante "implantar programas de educação e formação em direitos humanos, em parceria com entidades não-governamentais" (Brasil, 2002, p. 2). Diferentemente do primeiro PNDH, esta versão reduziu a urgência da preocupação com grupos de extermínio, citados apenas nos sistemas de proteção às crianças e adolescentes e na repressão de órgãos de comunicação que, porventura, estimulassem essa prática.

\section{Metodologia}

Este trabalho tem como principal objetivo analisar o significado e a importância dos direitos humanos no Brasil quando visto pela ótica da população quanto aos temas da liberdade de crença e da atuação das forças policiais após o período ditatorial vivido pelo país entre 1964 e 1985. Visando a atender ao objetivo proposto pela pesquisa, aborda-se a questão dos direitos humanos na história contemporânea, contextualizando-a no cenário político brasileiro à época, a partir de manifestações de leitores de uma revista semanal brasileira sobre questões relacionadas aos direitos humanos. A revista escolhida foi a ISTOÉ, criada em 1976 pelo empresário Domingo Alzugaray, e publicada pela Editora Três. A escolha se deu pela aceitação e circulação nacional da revista, pela existência de uma seção destinada à apresentação de opiniões diversas dos leitores sobre as reportagens por ela apresentadas em edições anteriores e pela atual disponibilização da seção de manifestação dos leitores daquele período.

O recorte temporal definido para essa análise foi o compreendido entre os anos de 1985 e 2004, ou seja, exatas duas décadas após o fim ditadura civil-militar brasileira. A primeira motivação para essa escolha é que a partir da metade da década de 1980 iniciou-se um processo de redemocratização da política brasileira, com medidas que evidenciavam a redução crescente do rigor do governo militar, bem como a anistia dos brasileiros condenados durante os governos militares. Paralelamente aos esforços para a redemocratização do processo político, emergiu um movimento destinado à criação de uma nova Constituição da República, que foi promulgada em 1988. Em 1989, nesse clima de abertura política, realizou-se a primeira eleição direta para a Presidência e elegeu-se o alagoano Fernando Collor de Mello, que à época tinha 40 anos, tendo sido o mais jovem presidente brasileiro. Após mais de um ano de mandato, o presidente foi acusado de corrupção, houve uma forte crítica ao seu projeto econômico e a outras ações do governo, o que resultou na aprovação do seu impeachment. em 29 de setembro de 1992. Na oportunidade, o vice-presidente Itamar Franco resguardou-se da situação, desfiliou-se do partido do presidente - o PRN - e assumiu o governo. Como presidente, Itamar Franco preocupou-se com a economia e entregou o Ministério da Fazenda ao sociólogo Fernando Henrique Cardoso, que com auxílio de um grupo de economistas, conseguiu implantar o Plano Real, que garantiu a estabilização da moeda brasileira. O sucesso desse plano gerou grande popularidade ao ministro, que em 1994 conseguiu eleger-se presidente, concorrendo com Luis Inácio Lula da Silva. Fernando Henrique tomou posse em $1^{\circ}$ de janeiro de 1995, e governou até $1^{\circ}$ de janeiro de 2003, quando Luiz Inácio Lula da Silva foi eleito e assumiu a presidência. 
A referência a todos esses eventos justifica a definição do recorte temporal, pois evidencia o envolvimento do povo com fatos políticos e econômicos e a tentativa de se restabelecer a discussão e a crítica popular no país. Na seção dedicada à exposição das falas dos leitores, as críticas a reportagens apresentadas pela revista nas semanas anteriores colocam à mostra os valores da sociedade daquela época. Desse modo, a seção da revista transformou os leitores do periódico em produtores de conteúdo passível de consumo por outros integrantes da sociedade, inclusive na defesa e difusão dos direitos humanos. Essa escolha temporal se justifica, ainda, por se tratar de um período em que a discussão sobre direitos humanos teve grande repercussão no Brasil, por motivos políticos, após o regime ditatorial. Ademais, há, ainda, interesse acadêmico sobre uma possível mudança de entendimento da população brasileira ao longo desses vinte anos escolhidos para análise, já que tanto as forças policiais quanto aqueles que professavam outras fés que não a cristã católica eram alvos de crítica e rejeição.

Trata-se de uma pesquisa qualitativa, que adota revisão bibliográfica e coleta de informações documentais, reunindo dados buscados no espaço reservado aos leitores da revista ISTOÉ dos anos 1980 e seguintes. Para análise dos resultados coletados, a pesquisa se vale da análise de conteúdo e usa a categorização para proceder à análise das opiniões emitidas pelos leitores. Conforme se destaca Bardin (2011), trata-se de um conjunto de instrumentos usado para um desvendar crítico focado na temática abordada, apropriado para fontes jornalísticas.

\section{Resultados e Discussão}

Ao longo dos vinte anos analisados neste trabalho, a coluna teve inicialmente o nome "Com a palavra" (1985-1988) e posteriormente "Cartas" (1988-1998). Também em 1988 houve alteração de nome da revista para ISTOÉ Senhor, voltando a se chamar apenas ISTOÉ em 1992. A partir de 1996, a revista passou a ter uma versão eletrônica para a internet e a partir de 1999 passou a disponibilizar todo o seu conteúdo de maneira gratuita em meio digital. Tratando-se de uma revista de circulação nacional, a quantidade de cartas de leitores recebidas pela redação era alta e lembra-se que o editor exercia um papel de importância decisiva, devendo selecionar, em tese, aquelas que imaginava serem de interesse comum para a publicação (Pereira Júnior, 2011). Na pesquisa ora apresentada foram coletadas as opiniões dos leitores sobre a liberdade de crença e a atuação dos responsáveis pela segurança pública, questões diretamente ligadas aos direitos humanos. Uma vez estabelecido o recorte temporal, foi o mesmo dividido em períodos de cinco anos, que são os seguintes: Período 1, de 1985 a 1989; Período 2, de 1990 a 1994; Período 3, de 1995 a 1999; e Período 4, de 2000 a 2004.

\subsection{Período 1: introdução da nova Constituição, críticas ao cristianismo e insatisfação com a atuação das polícias}

O Período 1 se refere ao primeiro quinquênio, reunindo o material coletado na seção da revista no período de 1985 a 1989, fase que no Brasil é marcada pela transição do ciclo de governantes militares para o ciclo de governantes civis. As cartas dos leitores fazem referência a temas religiosos, com realce à liberdade de crença - em algumas ocasiões mesclada a atitudes preconceituosas contra pessoas negras -, a atos de violência cometidos por policiais, sendo todas essas citações referentes ao respeito aos direitos humanos.

Observa-se que, quase $90 \%$ das opiniões dos leitores faz referência a temas religiosos e verifica-se a prevalência das religiões de matriz judaico-cristã na sociedade brasileira, tanto na época estudada quanto nos períodos anteriores. Das 89 cartas publicadas, 47 fizeram menção exclusivamente ao catolicismo. Outras 18 mencionam as vertentes religiosas de caráter protestante e 14 cartas mencionaram as duas correntes religiosas ao mesmo tempo.

Ainda no que se refere às crenças religiosas, mereceu destaque entre os comentários a crítica à produção cinematográfica "A última tentação de Cristo", filme lançado em 1988, que pretendeu fazer uma releitura da narrativa bíblica, apresentando Jesus de Nazaré com uma personalidade cercada de fragilidades e incertezas, construindo uma hipotética narrativa ficcional de sua vida, caso escolhesse viver de forma comum. O filme chegou ao Brasil já na vigência da 
Constituição da República de 1988 e, por isso, não sofreu nenhum tipo de censura formal, embora os líderes da Igreja Católica no Brasil fizessem forte oposição à sua exibição em território nacional.

Ainda em 1988, a revista publicou um editorial intitulado "O poder e os dogmas" criticando a postura da Igreja Católica face à obra de arte. O editorial motivou a publicação de oito cartas de leitores distribuídas ao longo de dezessete semanas. É oportuno citar uma dessas cartas:

A respeito da exibição ou não do filme "A última tentação de Cristo", sou de opinião que, num país democrático, o máximo que a CNBB deva fazer é recomendar aos fiéis católicos que não vejam. O resto, é escolha individual e pleno exercício do direito de cidadão. Não sou católica, apesar de ter sido batizada quando nasci, mas sou uma pessoa de filosofia cristã, mesmo que não esteja filiado a qualquer Igreja. O fato de ser cristã não me impede de ver o filme, de analisá-lo e de criticá-lo. Eu decido se devo ou não vê-lo. Não dou o direito a CNBB decidir por mim, assim como garanto que milhares de brasileiros também não conferem carta branca a Igreja Católica, simplesmente pelo motivo de que não são católicos. E nesse país, há milhares de pessoas que não são cristãs, quanto menos, católicas. Não é uma prepotência da CNBB usar seu poder para impor sua censura? (ISTOÉ, 1988, p. 16)

Opiniões como a deste leitor refletem o curso de um processo de individuação a partir da destradicionalização, tal como indica Martuccelli (2007), ao observar que nesse processo já não se aceita que as instituições religiosas possam regular o que as pessoas podem ou não fazer.

Considerando ainda as cartas publicadas na seção em análise, verificou-se que 40 leitores opinavam de forma positiva a respeito de alguma das correntes religiosas ou defendiam a convicção ética dessa corrente. Dentre esses leitores, 24 se posicionavam de maneira favorável à corrente religiosa católica, enquanto apenas cinco se posicionavam de maneira favorável ao protestantismo. A referência às religiões de origem africana não aconteceu no período mencionado e apenas uma carta publicada apresentava um ponto de vista favorável à Umbanda e ao Candomblé. Nesse caso, a crítica à liberdade religiosa se mescla à discriminação contra pessoas negras, como se vê no comentário feito sobre a reportagem "Honra à negritude", indicando fontes complementares de informações a respeito da repressão policial aos cultos de matriz africana:

Na reportagem Honra à negritude (ISTOÉ n. ${ }^{\circ}$ 587) é citado um estudo desenvolvido pelo prof. Júlio Braga, da Universidade Federal da Bahia, sobre a repressão policial ao Candomblé. Gostaria de informar ao referido professor e a outros que tenham interesse no assunto que o Museu da Academia de Polícia do Rio de Janeiro possui um acervo importantíssimo e infelizmente ainda bastante desconhecido sobre o culto da Umbanda e Candomblé referente às primeiras décadas do século XX quando tais práticas eram reprimidas policialmente (ISTOÉ, 1988, p. 39).

Esta carta permite identificar uma rejeição a tais atitudes preconceituosas contra negros, que eram associados às religiões de matriz africana, mas também aponta o comportamento repressivo dos policiais, sendo ambas as questões consideradas desrespeito aos direitos humanos.

Quando são tomadas as opiniões de aspecto negativo por parte dos leitores, contabilizam-se 40 cartas, dentre as quais cerca de 20 demonstraram clara insatisfação com o posicionamento da Igreja Católica em relação às produções cinematográficas e à crítica a outras religiões. Existem, também, 10 leitores que registram críticas voltadas exclusivamente para o segmento protestante. Três deles concentram suas críticas sobre o líder da Igreja Universal do Reino de Deus (Igreja Universal), Edir Macedo e se referem ao uso do dinheiro das doações:

Ao ler a matéria "em nome de Deus", sobre a seita de Edir Macedo, (ISTOÉ n. ${ }^{\circ} 1053$ ), confesso ter sido tomada de grande tristeza, por ver o nome de Deus sendo difamado por homens sem escrúpulos que só pensam em fazer fortuna. Com referência ao dízimo, o que se tem lido no capítulo 3, do livro de Malaquias, versículo 6 ao 12, é que ele deve ser usada para ajudar aos necessitados para que não falte para estes o alimento. A salvação que Deus oferece não tem nada a ver com quanto você recebe o quanto você vai dar, mas, cinco, ao quanto você vai deixar que Ele faça por você (ISTOÉ, 1989, p. 21). 
Note-se que o leitor caracteriza o grupo de fiéis liderados pelo bispo Edir Macedo como sendo uma seita, expressão que, segundo Seiwert (2001), tem um caráter pejorativo. Um grupo menor, mas expressivo, formado por oito leitores, teceu comentários de aspecto negativo sobre católicos e de protestantes. Duas das cartas repercutiram a reportagem "O poder e os dogmas" que, embora fosse uma crítica voltada para o clero católico, criou margem para considerações a respeito dos grupos protestantes:

"Parabéns pelo artigo "O poder e os dogmas" do n 989. Já estamos no século XXI e as igrejas ainda não resolveram ensinar o homem a pensar, e sim a mantê-lo preso a dogmas, mistérios etc [...]" (ISTOÉ, 1988, n.p.).

O Candomblé também foi alvo de uma consideração negativa por parte de um leitor aparentemente cristão. Ao repercutir a reportagem "Samba perde ala da fé", o leitor considera que parte dos problemas do Brasil estão associados ao Carnaval e ao Candomblé:

A reportagem Samba perde ala da fé (ISTOÉ no 578 ) mostra-nos algo que está acontecendo não só no Rio mas em todo o Brasil. Jesus está libertando pessoas que estão cansadas das ilusões e da falsa felicidade que o Carnaval traz. É uma pena que enquanto o Brasil se afunda na miséria, pessoas sejam enganadas e gastem o pouco dinheiro que tem durante os quatro dias de Carnaval, para depois passar em um ano todo reclamando da vida. O Brasil melhorará quando esquecer o Carnaval e o Candomblé e se voltar para Jesus. (ISTOÉ, 1988, p. 35).

Como se pode observar, o Candomblé e o Carnaval são associados no comentário do leitor e são indicados como raízes do atraso econômico do país. A solução para o problema, de acordo com o leitor, estaria na adesão completa ao cristianismo, que levaria as pessoas a usarem de forma adequada o dinheiro, evitando a miséria, a adesão à folia e aos cultos considerados impróprios. Algumas cartas do período fizeram menção ao judaísmo, ao mormonismo, à Igreja Messiânica e ao misticismo de maneira geral, o que se considera, no caso, defesa de pontos de vista religiosos como respeito aos direitos humanos.

No período de 1985 a 1987, apenas cinco cartas de leitores fizeram alguma referência às polícias, todas elas mencionando algum ato de violência cometido por policiais. Como exemplos, citam-se duas cartas:

A Polícia Militar paulista reprimiu com violência, no sábado, 12, boias-frias que faziam piquetes de greve em Guariba, cidade a 360 quilômetros de São Paulo e uma das maiores produtoras de cana-de-açúcar do país. Os trabalhadores protestavam contra os usineiros da região que não cumpriram o acordo assinado em maio do ano passado - pagamento de salário mínimo diário de 20 mil cruzeiros e estabilidade de um ano no trabalho. O episódio documentado pela televisão - causou grande indignação em todo o país (ISTOÉ, 1985, p. 75).

A sociedade brasileira, estarrecida toma conhecimento de mais uma violência policial - a bruta 'chacina de Pernambuco' (ISTOÉ $\mathrm{n}^{\circ}$ 427) -, exprimindo a urgência de se aplicar uma reforma profunda e radical nas nossas fileiras policiais, a começar pela abolição da prática da filosofia de que policial e violência são inseparáveis. A punição rigorosa aplicada direta ou indiretamente (mesmo àqueles que tentam proteger os culpados) não trará os mortos de volta à vida, mas certamente evitará que outros inocentes sejam tragados pelo estímulo à violência que a impunidade oferece (ISTOÉ, 1985, p. 82).

Observa-se, pelos exemplos acima, a insatisfação de leitores que pretendem não mais tolerar ações policiais violentas. Essa insatisfação coincide com um período muito delicado para as instituições, visto que a nova Constituição estava prestes a ser discutida. Os resquícios da doutrina de segurança nacional na formação Policial Militar bem como a sua mimetização com o Exército Brasileiro fizeram com que o modelo policial fosse discutido na Assembleia Nacional Constituinte (1987-1988), questionando o caráter militar das forças policiais. 


\subsection{Período 2: ascensão do espiritismo, fortalecimento do protestantismo e o massacre do Carandiru}

Refere-se ao segundo quinquênio, de 1990 a 1994, fase que sucede a promulgação da Constituição da República de 1988, a implantação das eleições diretas, aspectos que marcam o avanço do processo de redemocratização do país. No início dos anos 1990, a Santa Sé já deixava clara sua insatisfação com os rumos tomados pela ala progressista da Igreja Católica na busca de melhoria social para a classe mais pobre. Por outro lado, o protestantismo ganhou maior aceitação, ampliando significativamente o número de adeptos, ganhando corpo o movimento liderado pelo bispo Edir Macedo.

Analisando-se o periódico, vê-se que na primeira metade dos anos 1990 foram publicadas 28 cartas de leitores, das quais 10 fizeram menção exclusivamente ao catolicismo; outras seis se referiam a vertentes religiosas de caráter protestante. A doutrina espírita, até então pouco comentada, surgiu nesse período com maior força no cenário religioso brasileiro, chegando a ser comentada nas cartas de seis leitores neste período. Tendo em vista que o espiritismo, codificado por Allan Kardec a partir de 1857, também é considerado uma das vertentes do cristianismo, infere-se que os comentários se mantém em torno da doutrina cristã.

Das 10 menções feitas exclusivamente ao catolicismo, seis contestavam o que foi denominado "reacionarismo católico" (ISTOÉ, 1990, p. 8), um esforço dos líderes da Igreja Católica para retomar o aspecto espiritual da igreja, pouco valorizado em face da teologia da libertação, de caráter mais materialista.

Muito oportuna a reportagem "À direita de Deus" (ISTOÉ n. ${ }^{\circ}$ 1089), no momento em que o reacionarismo católico avança a passos largos e com pesadas botas. Em rápido esboço, o clero conservador pode ser caracterizado por seus aspectos teológico, histórico e psicológico. Quanto ao primeiro, impõe-se a questão metodológica: a sua limitação ao embasamento filosófico ("a philosophia perenis"), recusando os subsídios da Ciências Sociais. Em relação ao histórico, a hegemonia absoluta da divindade do Cristo, em prejuízo da figura humana de Jesus, isto é, a desumanização do cristianismo. E, no que se refere ao psicológico, a exigência do centralismo, da obediência cega ao Papa, mesmo em questões não dogmáticas, levando-a a certa imaturidade, ao que se poderia chamar de infantilismo perverso, o qual nada tem em comum com lado criança, afetivo-intuitivo, próprio da fé cristã. Enfim, o conservadorismo mais voltado para o futuro celestial do que para o presente terrestre, deveria se questionar sobre o que será menos ortodoxo: o possível risco de uma maior participação ou a segurança usurária da TFP (Tradição, família e propriedade)? Afinal de contas, a história da igreja tem se mostrado um processo dinâmico, uma tensão dialética, entre o burocratismo esclerosado e a juventude renovadora (ISTOÉ, 1990, p. 8).

Este quinquênio foi marcado pela ampliação dos adeptos do protestantismo, sendo que a Igreja Universal já estava também presente em diversos outros países e adquirido a Rede Record de Televisão. No campo teológico, a Igreja Universal é uma igreja protestante classificada como neopentecostal, cuja ênfase recai sobre o confronto espiritual direto contra espíritos malignos e a difusão da teologia da prosperidade. De acordo com essa teologia, cristãos fiéis são prósperos e não são acometidos por doenças ou outros problemas sociais. A principal estratégia apontada para superação de todos os problemas é o emprego da fé (Romeiro, 1993).

À época, o bispo Edir Macedo concedeu uma entrevista na qual fez clara oposição ao catolicismo, acusado de atrasar o desenvolvimento do país. Enquanto de um lado fica evidente a liberdade de crença, manifestação ligada aos direitos humanos, de outro lado chama a atenção a desconfiança de alguns leitores sobre o grande patrimônio da Igreja Universal e de seu líder, por ser este patrimônio adquirido com as doações e dízimos dos fiéis. As críticas contidas nas seis cartas seguem esta a seguir:

Como assinante e leitor de ISTOÉ, surpreendi-me ao abrir as páginas dessa conceituada revista (edição 1083) e deparar com entrevista com pastor Edir Macedo. Não é difícil de observar as intenções do Senhor Edir com relação ao seu Deus particular. Curioso é que ele trocou "imposto" por "dízimo", mas... Se Cruzeiro já foi cruzado isso é inflação está em 0,1 até possível que ele mesmo seja mais um herói nosso, uma nova concepção para as fantasias carnavalescas do dia a dia! Deus que nos perdoe!!! Parabéns aos entrevistadores. Eles conseguiram arrancar palavras claras do nosso pastor (ISTOÉ, 1990, p. 8). 
Comentários negativos sobre as religiões de matriz africana passaram a ser expostos claramente nas cartas dos leitores. As críticas aos rituais da Umbanda são utilizadas, inclusive, para caracterizar negativamente os cultos de libertação usados por algumas igrejas protestantes, cujos pastores também são criticados:

Parabenizo pelas atuações junto a esses falsos pastores milagreiros dessas seitas clientes que proliferam por aí. Os "cultos de libertação" que promovem às sextas-feiras não difere em nada de qualquer sessão de Umbanda, inclusive baixando caboclos nos presentes. Concluí que os que se apegam a essas seitas também são mesmo muito chegados ao espiritismo, e a um "terreiro" às sextas-feiras. Esses pastores são mesmo caso de polícia; são autênticos larápios! Esses pastores, informou-me uma filha de um deles, aperfeiçoam-se ao máximo em hipnose individual e coletiva! (ISTOÉ, 1990, p. 10)

Na primeira metade da década de 1990, os comentários sobre o espiritismo surgiram como novidade entre as cartas dos leitores, sendo a maior parte deles de caráter negativo. Duas dessas cartas combatiam a reencarnação, que é um dos aspectos doutrinários mais populares do espiritismo. Uma terceira carta trouxe a indicação da parapsicologia como ciência capaz de explicar os fenômenos que ocorrem nas sessões espíritas, enquanto outra acusava a doutrina espírita de contribuir para a alienação do povo. As críticas feitas expressam abertamente intolerância com as correntes religiosas que coexistem dentro do território brasileiro, fato pouco comum até então.

Outras cartas de leitores apresentam críticas às ações da polícia, incluindo tanto a Polícia Civil quanto a Polícia Militar. Duas cartas fazem menção à reportagem "Mais uma vergonha", publicada na revista ISTOÉ, n. ${ }^{\circ}$ 1071. A citada reportagem narrou a malograda intervenção da Polícia Militar do Estado de São Paulo na resolução de uma ocorrência de sequestro. Com o acirramento dos ânimos e a complexidade da ocorrência, os policiais militares fizeram opção pelo emprego de um atirador de elite, que com um só tiro, atingiu o sequestrador e a vítima, levando-os à morte. Na ocasião, alguns leitores expuseram toda a sua insatisfação com a atuação da polícia que, por vezes, se mostrava violenta e arbitrária:

Sr. Diretor: Queria parabenizar a Beatriz Fragelli e seus colaboradores pela corajosa matéria "Insegurança armada" (ISTOÉ n. ${ }^{\circ}$ 1072). Mais do que coragem, necessita a coletividade onde policiais e assassinos se confundem no exercício da prepotência, truculência e usurpação do poder. Necessita muito da sorte de não esbarrar nessas falanges oficializadas e não enquadrar-se num dos inúmeros itens que traçam o perfil do "suspeito". Parece, triste ironia, que a polícia inventou uma fórmula de impedir espancamentos, latrocínios, sequestros, estupros etc: eliminar as vítimas potenciais, a população, antes dos marginais. Sem vítimas, não haverá mais crimes. Segundo George Orwell, a forma mais eficaz de um homem demonstrar seu domínio sobre outro é fazendo-o sofrer, e assim atuam nossas sádicas milícias repressivas, ao doce sabor da impunidade (ISTOÉ, 1990, p. 9).

Esse erro policial, encarado pelos leitores como assassinato, foi repercutido de forma direta e indireta por três das seis cartas publicadas em 1990 com os assuntos aqui pesquisados. Outro evento policial de indiscutível relevância foi a intervenção da Polícia Militar do Estado de São Paulo no pavilhão 9 da Casa de Detenção de São Paulo. Ocorrido em 2 de outubro de 1992, o episódio ficou conhecido como "O Massacre do Carandiru", no qual 111 presos foram mortos por disparos de armas de fogo realizados pelos policiais militares. Diante do incidente trágico, identificou-se duas cartas de leitores, que repercutiram o ocorrido na casa de detenção, sendo esta a mais incisiva:

O discurso de um país que se diz democrático é que a penitenciária existe com o fim de resgatar o indivíduo para adaptá-lo à sociedade. Ora! Muito bem! Às vésperas do maior exercício da democracia, que é o voto, o País ficou estarrecido dando mostras que o autoritarismo está vivo. Mais de 150 seres humanos foram chacinados pela polícia de São Paulo. Justamente no momento em que se comemora o impeachment de Collor. Penso que estamos retroagindo aos anos 60, quando as pessoas eram mortas de forma absurda (ISTOÉ, 1992, p. 8).

Outras três reportagens continuaram a repercutir fortemente a intervenção malsucedida da Polícia e as reportagens "O primeiro tiro" e "Prova sem retoques", ambas de 1992, contribuíram para colocar em xeque a estratégia e a transparência da 
atuação policial. O relatório de uma das diretoras da Organização dos Estados Americanos (OEA) expôs a percepção das investigações do fato:

As autoridades cometeram abusos contra os prisioneiros sobreviventes, trataram os parentes com extrema insensibilidade e, até o momento, não demonstraram estar dispostas a conduzir uma investigação em boa-fé nem a tomar medidas que evitem novos atos arbitrários (Oliveira, 1992, p. 34).

Observou-se por todo o período analisado que as queixas referentes ao desrespeito aos direitos humanos contra as corporações policiais brasileiras - sobretudo as Polícias Militares - estão relacionadas aos abusos corporais e assassinatos arbitrários.

\subsection{Período 3: embates entre católicos e protestantes, crescimento da pluralidade religiosa e aprovação do PL sobre os crimes de tortura}

Este período, de 1995 a 1999, foi marcado por mudanças em diferentes setores da sociedade. No plano político, o primeiro presidente da república eleito diretamente sofreu impeachment e em seu lugar assumiu a presidência o mineiro Itamar Franco. No plano socioeconômico, houve o lançamento do Plano Real, que conseguiu debelar os altos índices de inflação, contra os quais vários planos econômicos anteriores fracassaram. Neste período, no campo dos direitos humanos, as manifestações de leitores da revista ISTOÉ deram realce a assuntos religiosos, mostrando a tendência instalada na sociedade de se respeitar a liberdade de crença. Outros comentários abordaram a violência policial, visando à defesa dos direitos das pessoas ameaçadas por ações policiais.

No tocante às manifestações sobre crenças religiosas, a polarização do assunto continua sendo a disputa entre católicos e evangélicos, o que deriva do crescimento evangélico em todo o Brasil. Entretanto, a revista também abordou outras religiões, tais como o espiritismo e mesmo o judaísmo, quando abordou o trabalho de evangelização dos judeus, bem como a conversão do pugilista Myke Tyson ao islamismo. Abordou também a convivência pacífica entre muçulmanos e católicos no Timor Leste, enquanto os dois grupos estavam no centro de um conflito étnico na Bósnia. Essas reportagens divulgadas pela revista são responsáveis pelos comentários enviados pelos leitores.

Nesse quinquênio, foram localizadas 106 cartas relacionadas a temas de fundo religioso. Dessas, 35 fizeram referência exclusiva ao catolicismo; outras 31 fizeram referência exclusiva ao protestantismo e nove outras fizeram referência às duas correntes religiosas ao mesmo tempo. O espiritismo foi comentado em 11 cartas remetidas à redação do periódico. Juntas, essas três correntes religiosas do cristianismo detiveram $81 \%$ dos comentários enviados à revista, sendo 20 cartas relacionadas a outras religiões ou práticas religiosas.

Merece atenção a repercussão dada pelos leitores ao surgimento de uma nova "seita" liderada por Inri Thais conhecido como "Inri Cristo" - que declarava ser a reencarnação de Jesus Cristo e se vestia da forma como o senso comum imagina o Jesus descrito nos textos bíblicos. Seu templo foi denominado Suprema Ordem Universal da Santíssima Trindade (SOUST). Opiniões expressas nas cartas dos leitores da ISTOÉ, evidenciam a baixa tolerância da sociedade brasileira diante da diversidade religiosa: "[f]iquei decepcionada ao ver uma revista tão séria dar tamanho destaque a um maluco fanático como Inri Thais” (ISTOÉ, 1997, n.p.), e “[o] fanatismo cada dia que passa prolifera; já tem até meros seres humanos dizendo ser Jesus Cristo. Já não basta a Mãe Dinah?” (ISTOÉ, 1997, n.p.).

Entre os anos de 1995 e 1999, houve grande expansão de expressões religiosas, sobretudo dentro do cristianismo protestante. A Igreja Universal voltou a ser criticada pelo uso das doações feitas pelos fiéis e pela intolerância em face do catolicismo. $\mathrm{O}$ ato de intolerância considerado mais grave foi o episódio conhecido como "chute na santa", no qual um bispo da Igreja Universal chutou uma imagem religiosa representativa de Nossa Senhora de Aparecida, durante um programa de televisão, em 12 de Outubro de 1995. O caso repercutiu negativamente contra todos os protestantes, sobretudo contra aqueles 
ligados à Igreja Universal. O posicionamento de uma das leitoras deixa isso muito claro, quando ela diz que "se os protestantes querem destruir nossas imagens, que o façam. Há dentro de nós um sentimento que transcende a imagem. E isso ninguém pode destruir" (ISTOÉ, 1995, p. 10).

Essa e outras graves circunstâncias fizeram com que o protestantismo atraísse contra si a opinião de 25 dos 106 leitores que se manifestaram a respeito de temas religiosos nas páginas da revista ISTOÉ no período de 1995 a 1999.Já na corrente católica, foram encontradas 16 cartas com opiniões negativas sobre o comportamento sexual de padres ou a posição do Papa, mas as críticas não atingiam a questão dos direitos humanos.

Neste período, deve-se destacar o crescimento do espiritismo entre os brasileiros e várias produções culturais, entre elas a novela "A Viagem", da Rede Globo de Televisão, impulsionaram a divulgação de um dos pontos da doutrina espírita que mais desperta o interesse: a reencarnação. Entre as cartas dos leitores, 11 criticaram a cobrança de valores vultosos por videntes de religiões espiritualistas.

As referências positivas ao espiritismo mostram maior aceitação dessa postura religiosa, ressaltando o interesse pelos temas da mediunidade e reencarnação. A figura do médium Francisco Cândido Xavier, o Chico Xavier, é exaltada pelo respeito ao ser humano e por sua vida simples e abnegada.

Lendo a chamada para entrevista "todos somos médiuns" (ISTOÉ 1333), como físico francês Patrick Drouot, resolvi verificar o que o cientista da terra de Allan Kardec descobriu. É decepcionante perceber que um pesquisador da mediunidade e da reencarnação não conhece Francisco Cândido Xavier, maior médium deste século e o melhor ser humano da terra. A ciência continua cega em matéria de espírito (ISTOÉ, 1995, n.p).

Percebe-se, pois, que no período, a pluralidade religiosa cresceu e aflorou no Brasil, provocando convulsões sociais entre os fiéis de cada corrente religiosa. Mesmo em meio a tantas denúncias de abuso da fé, um dado chamou a atenção em uma pesquisa realizada pela Revista ISTOÉ e pela Rádio Bandeirantes, que ouviu 414 pessoas. Cerca de 98,8\% dos entrevistados ainda mantinham sua crença em Deus, mesmo sem professar nenhuma religião. Já as religiões de matriz africana não foram alvo de comentários dos leitores no período.

Poucas cartas dos leitores foram escritas entre os anos de 1995 e 1999 sobre o comportamento dos policiais, já que no período se implantavam medidas destinadas a introduzir o respeito aos direitos humanos na formação e nas ações dos policiais, que ainda tinham como tônica a violência, a existência de grupos de extermínio e os abusos de autoridade no eixo Rio-São Paulo.

A repórter Luciana Leal indicava, em uma matéria, que a inversão de valores continuava progredindo na sociedade brasileira e relatava que numa ocorrência de assalto um cinegrafista teria flagrado o momento em que o criminoso era arrastado para trás de uma Kombi e executado por um dos policiais que o prendeu. Embora o policial militar tenha sido preso por esse crime, a repórter afirmava que houve apoio popular à atitude do policial. Durante o ano de 1994, um total de 114 policiais militares tiveram suas vidas perdidas enquanto combatiam o crime e nos dois primeiros meses de 1995, sete outros policiais militares foram assassinados. Diante desse cenário sociopolítico, contabilizaram-se apenas 16 cartas ao longo desses cinco anos. Três das cartas repercutiram, em uma única edição, a já citada ocorrência em que um suspeito de cometimento de crime é levado para trás de um veículo e executado com um tiro.

A reportagem 'Show da morte' (ISTOÉ n. ${ }^{\circ}$ 1328) mostra um ótimo perfil do cabo Flávio e aponta acertadamente para curta distância que separa policiais e bandidos no Rio de Janeiro, e não somente aqui. No país, o relacionamento das autoridades com a população já de há muito é marcado por desrespeito e desconfiança. Quando a coletividade aplaude a forma como o cabo eliminou o bandido Cristiano, ver se como instituições desacreditados estão levando o homem comum a rever seus conceitos de vida civilizada (ISTOÉ, 1995, n.p) 
A carta desse leitor deixa claro o grau de violência a que a população brasileira estava submetida, sobretudo no Rio de Janeiro, e expõe também a aprovação popular ao ato de extermínio e a falta de confiança de parte dos brasileiros nas instituições responsáveis pela segurança pública e a justiça. Um fato que chamou a atenção dos leitores foi a ação policial realizada pela Polícia Militar do Estado de São Paulo na cidade de Diadema. A reportagem "Polícia bandida", veiculada na edição n. $^{\circ} 1436$, denunciou o abuso de poder e a violência policial durante uma abordagem que culminou na morte de um morador. As imagens das agressões policiais foram captadas por um cinegrafista no dia 7 de Março de 1997 e transmitidas pela televisão para todo o Brasil em horário nobre. O personagem mais conhecido em mais esse escândalo policial foi o soldado Otávio Lourenço Gambra, "o Rambo", que liderou uma série de agressões e, por fim, desferiu um disparo de arma de fogo na nuca de um dos abordados, levando-o à morte. Na edição seguinte, as críticas na seção das cartas dos leitores foram avassaladoras. Numa delas, um leitor de Curitiba afirma que "[n]a verdade temos duas alternativas à selvageria policial: uma é a extinção da Polícia Militar e outra é a criação de um órgão para nos proteger da polícia” (ISTOÉ, 1997, p. 8).

Após esse fato, surgiram denúncias feitas em diferentes estados do Brasil, apontando a conduta agressiva de policiais militares (Alves Filho, 1997), o que evidenciava a descrença da população sobre a capacidade da polícia de assegurar os direitos mais básicos das pessoas, como o direito à vida. Em apenas uma edição, 10leitores repercutiram a reportagem por meio de cartas à redação. Um leitor escreveu:"[n]ão encontro palavras para me expressar, tamanha é a minha vergonha devido a esse fato" (ISTOÉ, 1997, n.p.). Outro leitor reforçou o coro: "[a] polícia tem de ser exemplarmente punida (sic). Fico com vergonha de ser brasileiro" (ISTOÉ, 1997, n.p.).

Cabe aqui lembrar que desde 1994 estavam em andamento as discussões em torno do Projeto de Lei n. ${ }^{\circ} 4.716 / 94$, o qual buscava definir os crimes de tortura. Em outras oportunidades, o Governo Federal já tinha solicitado a votação em regime de urgência, porém apenas após esses fatos noticiados pela mídia é que as discussões foram concluídas e o projeto aprovado.

$\mathrm{O}$ foco das cartas dos leitores no período foi o repúdio à violência policial, ao abuso de autoridade e às execuções. Tais circunstâncias fizeram com que o Governo Federal criasse programas políticos de controle da violência, incluindo ações específicas voltadas para as forças policiais.

\subsection{Período 4: programas nacionais de direitos humanos, polícia comunitária e ISTOÉ digital}

Refere-se ao quinquênio de 2000 a 2004, o qual traz consigo as tentativas de implantação de programas de governo voltados para a segurança pública, com o objetivo que estancar o crescimento desordenado da criminalidade no Brasil. Na esfera internacional, em 11 de Setembro de 2001, terroristas de uma organização terrorista no Afeganistão realizaram a derrubada das Torres Gêmeas em Nova York, resultando na perda de aproximadamente três mil vidas. $\mathrm{O}$ acontecimento tinha, portanto, relação com o campo religioso e causou a perplexidade de habitantes de todo o mundo. O governo dos Estados Unidos passou a mobilizar o apoio de outros países na guerra contra o terrorismo, classificando os ataques como sendo contrários aos valores da civilização ocidental, um atentado aos direitos humanos (Camargo \& Rodrigues, 2001).

De acordo com a reportagem "União Impossível" (Magnoli, 2001), muçulmanos radicados nos Estados Unidos passaram a ser vítimas de agressões, uma vez que se criou uma associação entre a religião islâmica e o terrorismo. A partir desse atentado nos Estados Unidos, passou-se a perceber a presença de mais de um milhão de muçulmanos no Brasil, e na reportagem "Alá também é brasileiro" feita pouco mais de uma semana após os atentados, a revista ISTOÉ apontava tal fato e registrava a insatisfação dos muçulmanos brasileiros em serem associados aos terroristas.

No Brasil, em termos de políticas públicas, o Governo Federal lançou o Plano Nacional de Segurança Pública - PNSP (Brasil, 2000). Uma das medidas mais importantes adotadas pelo Plano foi a criação do Fundo Nacional de Segurança Pública, destinado a apoiar os estados no financiamento dos investimentos em Segurança Pública. O PNSP foi estruturado em quinze compromissos, e alguns deles se apresentam como relevantes para esse estudo. O Compromisso $n .^{\circ} 9$ buscava eliminar as 
chacinas e execuções sumárias, principalmente nas cidades do Rio de Janeiro, São Paulo, Salvador, Vitória e entorno do Distrito Federal. Visando a conter esses crimes, foram criados "mecanismos mais adequados de punição ao policial que se envolver em atividades criminosas" (Brasil, 2000, p. 22).O Compromisso n. ${ }^{\circ} 11$ buscava intensificar as ações do Programa Nacional de Direitos Humanos, criado em 1995, e o Compromisso n. ${ }^{\circ} 12$, destinado à capacitação profissional e reaparelhamento das polícias, teve a intenção de padronizar a capacitação dos policiais, principalmente nas atividades que demandavam a implantação da polícia comunitária. Tentou-se fazer a integração entre Polícia Civil e Militar, bem como estimular a profissionalização dos policiais e criar mecanismos e órgãos de controle da atividade policial.

Em 2002, foi lançado o Plano Nacional de Direitos Humanos - Fase II (PNDH-II), bem mais amplo que o primeiro. As 518 propostas buscaram proteger o direito à vida, à justiça, à liberdade, à orientação sexual, à igualdade, à educação, à saúde e previdência social, ao trabalho, à moradia, à alimentação, à cultura e lazer, dentre outros. O PNDH-II continuou investindo na estratégia educacional, visando a "implantar programas de educação e formação em Direitos Humanos, em parceria com entidades não-governamentais" (Brasil, 2002, p. 2).

Para os órgãos policiais, foi dada ênfase ao emprego da polícia comunitária, em que os laços entre polícia e comunidade local são estreitados a fim de garantir uma prestação de serviço de segurança pública de melhor qualidade e adequado a cada localidade. Este plano dá ênfase também ao direito e à liberdade de culto e se orienta para a prevenção e combate à intolerância religiosa, proíbe a veiculação de propaganda e mensagens racistas ou xenofóbicas e incentiva o diálogo entre movimentos religiosos, sob o prisma da construção de uma sociedade pluralista com reconhecimento e respeito às diferenças de crença e culto. (Brasil, 2002).

A partir de 1999, a Revista ISTOÉ passou a disponibilizar o seu conteúdo na web gratuitamente. Diferente dos períodos anteriores, neste quinquênio identificou-se apenas uma carta de leitor abordando assuntos relacionados à atuação de policiais. No caso, a carta constitui o desabafo de um leitor a respeito das diferenças salariais entre policiais e militares das Forças Armadas. Esse leitor considera que os baixos soldos contribuíam para a corrupção do policial militar da União. Não se registraram, neste período cartas dos leitores fazendo comentários sobre crenças religiosas nem críticas de um grupo de religiosos contra outros.

\section{Considerações Finais}

Este trabalho procurou analisar a questão dos direitos humanos relacionadas à liberdade de crença e à atuação das forças policiais na história contemporânea do Brasil pós-ditatorial, inserindo-a no cenário político e legislativo do período compreendido entre 1985 e 2004.A Declaração Universal dos Direitos Humanos foi adotada pela ONU em 1948, mas no Brasil os eventos políticos não oportunizaram manifestações populares a respeito do assunto.

Apesar da preocupação com os direitos humanos se evidenciar em diferentes momentos da história do país, foi somente na década de 1980 que ela se tornou relevante, quando significativas mudanças se efetivaram no campo político do país, culminando com a promulgação da Constituição de 1988. Trata-se, pois, de assunto atual, cujos reflexos se fazem presentes ainda nesta segunda década dos anos 2000, refletindo a complexidade do conceito dos direitos humanos, a importância das relações entre as instituições nacionais e especialmente entre as nações.

É, pois, a partir dos anos 1980 que a Declaração Universal de Direitos Humanos passou a constituir no país o marco inicial do sistema de proteção dos direitos humanos, que passaram exigir que suas crenças e religiões, assunto que perpassa inclusive questões étnico-raciais, e sua integridade física e psíquica fossem respeitadas, inclusive pelas forças policiais.

Na tentativa de mostrar esta tomada de posição, esse artigo apresentou a visão de leitores brasileiros a partir de suas manifestações no espaço de uma revista popular durante um período em que tais discussões sobre direitos humanos ganhavam 
notoriedade. O foco escolhido para esta análise foi sobre a liberdade de crença e a ação dos responsáveis pela manutenção da ordem pública e da segurança da população.

Foi possível inferir que a liberdade de expressão dos leitores, por meio da seção de cartas da revista, foi também utilizada como forma de amplificação de vozes e ideias sobre os assuntos aqui delimitados. Pôde-se ainda perceber que o a maioria católica deu lugar à pluralidade religiosa no período retratado, sendo as críticas a outras religiões mais presentes nos três primeiros quinquênios que no último. Por fim, notou-se que críticas dos leitores sobre a violência policial se estenderam por todo o período analisado, o que culminou em reestruturações e implementações de políticas públicas para aprimoramento das forças policiais. Assim, parece-nos que a consciência sobre os direitos humanos se define e se torna um conceito indispensável ao passo que uma sociedade adquire maturidade, sendo que sua efetiva aplicação emerge como consequência.

Uma limitação deste trabalho identificada desde logo e mencionada ao longo do texto consiste no papel decisivo e subjetivo dos editores da revista ISTOÉ.

É válido citar que os dados coletados neste artigo se restringem ao período em que a revista circulou com uma seção dedicada às opiniões dos leitores, não se buscando abordar fatos ocorridos a partir da segunda década dos anos 2000. Há, ainda, o período atual da história do Brasil, quando o clamor popular sobre o respeito aos direitos humanos parece se tornar mais sistemático e abrangente em diversas estruturas sociais. Nesse sentido, os autores enfatizam a necessidade de que novas pesquisas sejam realizadas, com o objetivo de se proceder à análise desses fenômenos atuais que estão diretamente relacionados aos direitos humanos e que constituem alvos dos comentários populares, assim como, sobre a época retratada neste trabalho, que se analise outras questões, incluindo o direito de se assumir papéis até então mais desempenhados por pessoas do gênero masculino; a liberdade de se assumir uma relação homossexual ou se assumir pessoa homo, bi ou transexual; a aceitação de pessoas de etnia ou de nacionalidade diferentes da maioria de um grupo; e demais práticas de grupos minoritários, por exemplo.

\section{Referências}

Alves, F., Filho. (1997). Um poder paralelo. ISTOÉ (1437), 35-36.

Barroso, L. R. (2013). “Aqui, lá e em todo lugar”: a dignidade humana no direito contemporâneo e no discurso transnacional. In Bogdandy, A., Piovesan, F., \& Antoniazzi, M. (Coords.). Direitos humanos, democracia e integração jurídica: emergência de um novo direito público. Elsevier, $413-464$.

Bardin, L. (2011). Análise de conteúdo. Edições 70.

Bobbio, N. (2004). A era dos direitos. Elsevier.

Brasil. (1996). Decreto $n^{o}$ 1.904, de 13 de Maio de 1996. Institui o Programa Nacional de Direitos Humanos - PNDH. http://www.planalto.gov.br/ccivil_03/decreto/d1904.htm.

Brasil. (2002). Decreto $n^{\circ} 4.229$, de 13 de Maio de 2002. Dispõe sobre o Programa Nacional de Direitos Humanos - PNDH, instituído pelo Decreto no 1.904, de 13 de maio de 1996, e dá outras providências. http://www.planalto.gov.br/ccivil_03/decreto/2002/D4229.htm.

Brasil. (1996). Plano Nacional de Direitos Humanos. Presidência da República.

Brasil. (2002). Plano Nacional de Direitos Humanos. (2a ed.) Presidência da República.

Brasil. (2000). Plano Nacional de Segurança Pública. Presidência da República. http://www.observatoriodeseguranca.org/files/PNSP\%202000.pdf.

Brasil. (1990). Projeto de Lei $n^{\circ} 5.239$, de 1990. Estabelece os crimes e as penas aplicáveis aos atos discriminatórios ou de preconceito de raça, cor, religião, etnia ou procedência nacional praticados pelos meios de comunicação ou por publicação de qualquer natureza. http://imagem.camara.gov.br/Imagem/d/pdf/DCD19JUN1990.pdf\#page=49.

Camargo, C., \& Rodrigues, A. (2001). No banco dos réus. ISTOÉ (1650), https://istoe.com.br/37334_NO+BANCO+DOS+REUS/.

Comparato, F. K. (2019). A Afirmação Histórica dos Direitos Humanos. (12a ed.) Saraiva.

Freitas, A. R., Jr., \& Piovesan, F. (2011). Direitos humanos na era da globalização: o papel do $3^{\circ}$ setor. In M. Garcia \& F. Piovesan (Orgs.), Teoria Geral dos Direitos Humanos. Revista dos Tribunais.

Jaspers, K. (1949). Vom Ursprung und Ziel der Geschichte. Piper Verlag. 
Research, Society and Development, v. 10, n. 11, e80101119394, 2021

(CC BY 4.0) | ISSN 2525-3409 | DOI: http://dx.doi.org/10.33448/rsd-v10i11.19394

Magnoli, D. (2001). União impossível. ISTOÉ (1669), https://istoe.com.br/41325_UNIAO+IMPOSSIVEL/.

Martuccelli, D. (2007). Gramáticas del individuo. Losada.

Messer, E. (1997). Pluralist Approaches to Human Rights. Journal of Anthropological Research, 53(3), 293-317.

Minas Gerais. (1994). Decreto Estadual $n^{\circ} 35.661$, de 27 de Junho de 1994. Aprova o Regimento Interno do Conselho Estadual de Defesa dos Direitos Humanos. Assembleia Legislativa de Minas Gerais. Belo Horizonte: Assembleia Legislativa de Minas Gerais. Recuperado em 16 de julho de 20201, de https://www.almg.gov.br/consulte/legislacao/completa/completa.html?tipo=DEC\&num=35661\&comp=\&ano=1994.

O Primeiro Tiro. (1992). ISTOÉ (1203), 55.

Oliveira, M. (1992). Prova sem retoques. ISTOÉ (1206), 26.

Pereira, L. C., Jr. (2011). Guia para a edição jornalística. Vozes.

Piovesan, F. (2014). Direitos humanos e justiça internacional: um estudo comparativo dos sistemas regionais europeu, interamericano e africano. 5. ed. São Paulo: Saraiva.

Preparar Mísseis. (2001). ISTOÉ (1668). https://istoe.com.br/41082_PREPARAR+MISSEIS/.

Romeiro, P. (1993). Supercrentes. Mundo Cristão.

Seiwert, H. (2001). O problema das "seitas" - Opinião pública, o cientista e o Estado. Revista de Estudos da Religião (2), 21-45. https://www.pucsp.br/rever/rv2_2001/p_hubert.pdf.

Trindade, A. A. C. (2010). International Law for Humankind: Towards a New Jus Gentium. Leiden: Martinus Nijhoff Publishers.

Últimos Números. (1996). ISTOÉ (1371), 19.

Villaméa, L. (2001). Alá também é brasileiro. ISTOÉ (1668). https://istoe.com.br/41223_ALA+TAMBEM+E+BRASILEIRO/.

Zanin, H., \& Soto, L. (2019). Violações à liberdade sindical nas ditaduras militares sul-americanas: reflexões a partir da Organização Internacional do Trabalho - OIT. In Freitas, A., Jr., \& Gomes, A. V. (Orgs.). O Centenário da Organização Internacional do Trabalho no Brasil. Fortaleza: Virtualis. $249-266$.

Zanin, H. (2021). Estudos sobre direitos humanos: transformações e consolidação no cenário contemporâneo. Revista do Curso de Direito do UNIFOR, 12(2), no prelo. 